- Encourages people to the hospice who would not usually feel able to just 'drop by'. 60,000 visits in the first year is estimated

- The information services have benefited more local people

- Reinvigorated support for the hospice.

Conclusion The Mill is changing public perception of hospice care, is providing informal means of support which complement existing hospice services and is generating more community engagement

\section{P-27 MEMORIES IN THE WIND, A FAMILY PICNIC}

Louise Johnson. St. Cuthbert's Hospice, Durham, UK

\subsection{6/bmjspcare-2016-001245.51}

Intergenerational projects are a cornerstone of community development. Through sharing information and experiences young people can engage a different perspective and experience situations that they might not usually be exposed to. It is in transforming the perceptions of our young people that we can initiate culture change.

We worked with a local youth project to approach four local schools, targeting 'A' level Art students. Three declined stating that it was inappropriate for their young people to come into the hospice, the remaining school circulated information to students and five young people came forward. Students came into the hospice (extra curricula), talked to day guests about memories, and planned a series of art installations in the hospice grounds to support our Dying Matters week collaborations. Some of the conversations challenged the young people, but the situation was managed by the team, without specialist support services. The aim for students was to understand life, death, grief and loss, gaining an understanding that death is part of life and should be embraced.

The art was robust and weatherproofed, objects suspended in the trees and walkways for an afternoon picnic. Our day guests were excited to share their memories, and the final exhibition proved emotional as the artwork resonated with many of the visitors. Exhibits included small pictures in glass jars, a globe, and a film in the following areas:

- Wedding

- Picnic

- Beach

- Coronation

- Family ribbon tree

- Railways

- World travel

- RAF

- Hiking

- Horse racing

- Washing line.

The timing of the event was difficult for the young people as it led into exam time - students found this difficult. Overall it was a successful event, students commented on the wisdom of older people and how life has changed, but most of all we now have a solid foundation with the school to build future relationships and learning.
P-28

PUBLICITY, PITFALLS AND PEOPLE - A HOSPICE ENTERS AN RHS SHOW GARDEN

Helen Briscoe. Primrose Hospice, Bromsgrove, UK

\subsection{6/bmjspcare-2016-001245.52}

The hospice was struggling with being known in the local community. This impacted on fundraising and also meant that potential patients weren't aware of services that could help them.

After discussions with a local garden designer a show garden was entered into the RHS Spring Festival at Malvern. Focussing on our children's bereavement support, it demonstrated visually the emotional journey that children experience when losing someone they love.

The aim was to use a nationally recognised 'vehicle' of an RHS flower show to promote our work to a wider audience and maybe make some money.

Sponsorship was sought including cash, goods, discounts and items being borrowed. Did you know you can 'borrow' a hedge? Well we did!

Volunteers and staff worked incredibly hard before, during and after the event doing so many supporting tasks.

We were delighted to win a bronze medal and more importantly win the People's Choice Award.

The publicity was amazing both pre- and post- event. Local, national and specialist publications ran our story. Local radio and TV took it up and our sponsors all promoted it so our social media ratings soared. Alan Titchmarsh even joined us on the garden and met the patients!

The impact on the people was phenomenal and was probably the most unexpected gain. The show garden was the most effective team build. The enthusiasm ran through volunteers, staff and even the patients who visited the garden one day. The visitors to the show all had a story to tell which was quite humbling at times and the pride the team showed whilst talking about our services was a joy to witness. Would we do it again? We don't know but never say never!

\section{P-29 EDUCATING THE EDUCATORS - HOW TO ENGAGE SCHOOLS IN HOSPICE CARE}

Gabi Field, Lawrie Mallyon. St Catherine's Hospice, Crawley, UK

\subsection{6/bmjspcare-2016-001245.53}

For adult hospices, engaging with schools is a challenge; many support children's charities. We wanted to engage with secondary schools, to educate them about hospice care, help to develop some key skills and get them fundraising.

Our Five-0 Project was aimed at secondary schools, who were challenged to recruit a team of six students and raise a minimum of $£ 1,500$ over 11 weeks from a start-up investment of $£ 50$.

We visited to talk about the project and what it would mean for the school. Recent reports from the government and the private sector have expressed the importance and benefits of Enterprise in education in today's schools. Schools were particularly engaged with the emphasis on business skills, innovation and supporting charity. We recruited seven schools including three new supporters. 